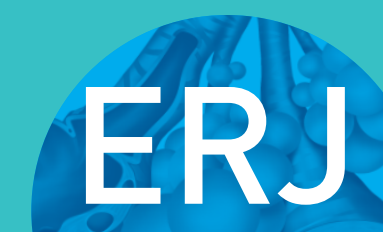

open research
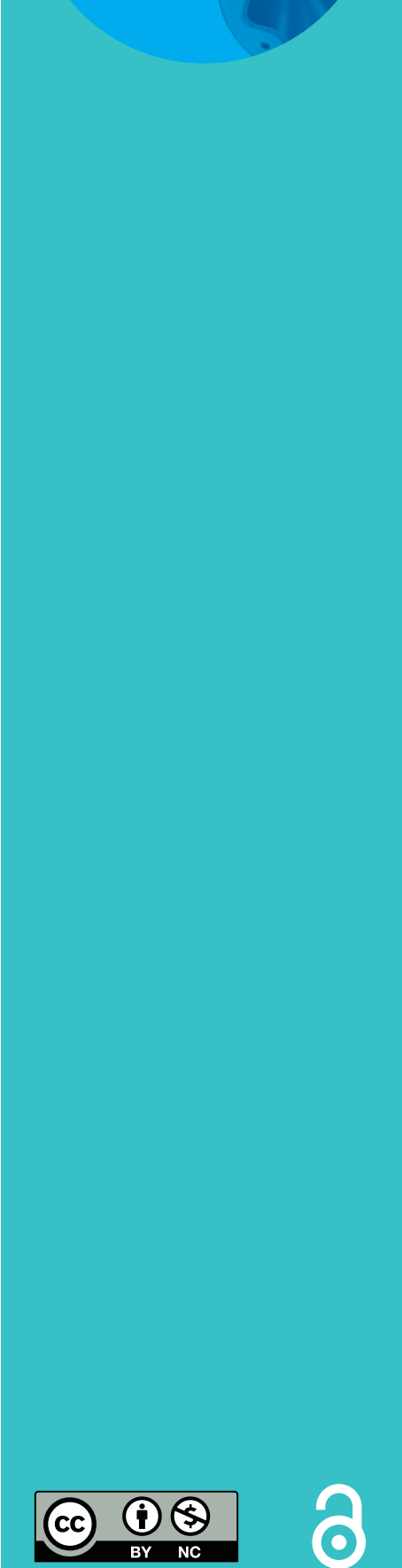

\section{Hydrogen peroxide in exhaled air: a source of error, a paradox and its resolution}

\author{
Stefan Peters ${ }^{1}$, Angelika Kronseder ${ }^{1}$, Stefan Karrasch ${ }^{1,6}$, Petra A. Neff ${ }^{2}$, \\ Matz Haaks ${ }^{3}$, Andreas R. Koczulla ${ }^{4}$, Petra Reinhold ${ }^{5}$, Dennis Nowak ${ }^{1}$ and \\ Rudolf A. Jörres ${ }^{1}$
}

Affiliations: ${ }^{1}$ Institute and Outpatient Clinic for Occupational, Social and Environmental Medicine, LudwigMaximilians-University, Munich, Germany. ${ }^{2}$ Robert Bosch GmbH, Stuttgart, Germany. ${ }^{3}$ Aero-Laser GmbH, Garmisch-Partenkirchen, Germany. ${ }^{4}$ Department of Internal Medicine, Division for Pulmonary Diseases, Philipps-University, Marburg, Germany. ${ }^{5}$ Institute of Molecular Pathogenesis at the Friedrich-LoefflerInstitute, Jena, Germany. 'Institute of Epidemiology I, Helmholtz Zentrum München, German Research Center for Environmental Health, Neuherberg, Germany.

Correspondence: Rudolf A. Jörres, Institute and Outpatient Clinic for Occupational, Social and Environmental Medicine, Ludwig-Maximilians-University, Ziemssenstraße 1, 80336 Munich, Germany.

E-mail: Rudolf.Joerresamed.uni-muenchen.de

ABSTRACT The concentration of hydrogen peroxide $\left(\mathrm{H}_{2} \mathrm{O}_{2}\right)$ in exhaled air has been reported to be elevated in asthma and chronic obstructive pulmonary disease (COPD), but results are inconsistent and difficult to reproduce. As $\mathrm{H}_{2} \mathrm{O}_{2}$ occurs in ambient air, we examined its association with exhaled $\mathrm{H}_{2} \mathrm{O}_{2}$ in human subjects.

Exhaled breath condensate (EBC) of 12 COPD patients and nine healthy control subjects was collected either with an inhalation filter (efficiency 81\%) or without. Ambient air condensate (AAC) was collected in parallel and samples were analysed for $\mathrm{H}_{2} \mathrm{O}_{2}$. Additionally, ambient $\mathrm{H}_{2} \mathrm{O}_{2}$ was recorded by an atmospheric measuring device (online fluorometric measurement).

$\mathrm{H}_{2} \mathrm{O}_{2}$ concentration in AAC was significantly higher $(\mathrm{p}<0.001)$ than in EBC. AAC variations were concordant with the data from the atmospheric measuring instrument. In both subjects' groups, the inhalation filter reduced $\mathrm{H}_{2} \mathrm{O}_{2}$ values $(\mathrm{p}<0.01)$. Despite generally low levels in exhaled air, analysis by a mathematical model revealed a contribution from endogenous $\mathrm{H}_{2} \mathrm{O}_{2}$ production.

The low $\mathrm{H}_{2} \mathrm{O}_{2}$ levels in exhaled air are explained by the reconditioning of $\mathrm{H}_{2} \mathrm{O}_{2}$-containing inhaled air in the airways. Inhaled $\mathrm{H}_{2} \mathrm{O}_{2}$ may be one factor in the heterogeneity and limited reproducibility of study results. A valid determination of endogenous $\mathrm{H}_{2} \mathrm{O}_{2}$ production requires inhalation filters.

$@$ ERSpublications

Use of an inhalation filter reduces variability of $\mathrm{H}_{2} \mathrm{O}_{2}$ values in exhaled air and shows an endogenous production http://ow.ly/TRmj300ee8t

Received: July 242015 | Accepted after revision: April 152016

Support statement: Supported by a grant from Robert Bosch GmbH and performed within the framework of the German Center for Lung Research (DZL), Munich.

Conflict of interest: Disclosures can be found alongside this article at openres.ersjournals.com

Copyright $\odot$ ERS 2016. This article is open access and distributed under the terms of the Creative Commons Attribution Non-Commercial Licence 4.0. 


\section{Introduction}

Over the past decades, noninvasive methods for assessing airway inflammation have been extensively studied, among these the analysis of exhaled breath condensate (EBC). A multitude of compounds have been detected in EBC; however, there always remained questions of validity and reproducibility [1]. This also holds for hydrogen peroxide $\left(\mathrm{H}_{2} \mathrm{O}_{2}\right)$ which has been studied in various diseases and conditions such as asthma [2-5], chronic obstructive pulmonary disease (COPD) [1, 6-10] and lung cancer [11, 12]. Some of these studies reported increased concentrations of $\mathrm{H}_{2} \mathrm{O}_{2}[3,7,9,12,13]$, but the questions of reproducibility and publication bias remain [14-16]. In principle, exhaled $\mathrm{H}_{2} \mathrm{O}_{2}$ is attractive as a potential marker of neutrophilic inflammation [11] and could be a clinical counterpart to exhaled nitric oxide (FeNO) as a marker often associated with eosinophilic inflammation $[2,11,17]$.

$\mathrm{H}_{2} \mathrm{O}_{2}$ also occurs in ambient air, predominantly in vapour form, which has been known since the 1870s [18] but has been rarely considered [19]. If the concentrations found in EBC are expressed as vapour in relation to water vapour, it turns out that the concentrations reported by SCHÖNE [18] as well as in meteorological papers $[20,21]$ are of the same order of magnitude as the values in EBC. Recent findings confirmed this, as $\mathrm{H}_{2} \mathrm{O}_{2}$ concentrations measured in exhaled air of calves, particularly in EBC, were significantly correlated with the ones assessed in ambient air [19]. In the present study, we aimed at a critical evaluation of the association between $\mathrm{H}_{2} \mathrm{O}_{2}$ concentrations in exhaled air and ambient air in human subjects, taking into account the reconditioning of air during inhalation via a mathematical model. In particular we addressed the question of whether the variability of measurements can be reduced by appropriate technical measures and what the contribution from endogenous $\mathrm{H}_{2} \mathrm{O}_{2}$ is relative to the estimated contribution from inhaled ambient air. Basically, the approach was to measure ambient $\mathrm{H}_{2} \mathrm{O}_{2}$ with the intention of computing the $\mathrm{H}_{2} \mathrm{O}_{2}$ concentration in exhaled air that is to be expected from unaltered inhaled $\mathrm{H}_{2} \mathrm{O}_{2}$ utilising a mathematical model and to compare these values with the measured values.

\section{Subjects and methods}

Study protocol

The study comprised two parts. The first part aimed at validating the measurement tools. For this purpose, ambient air was measured with a commercial atmospheric measurement device $\left(\mathrm{H}_{2} \mathrm{O}_{2}\right.$ AL2021 monitor; Aero Laser, Garmisch-Partenkirchen, Germany) and a commercial cooling system for collecting EBC (EcoScreen; Jaeger, Hoechberg, Germany; with improved collecting tube). The aim was to assess ambient $\mathrm{H}_{2} \mathrm{O}_{2}$ concentrations at varying levels, to establish the empirical relationship between EBC concentrations and atmospheric vapour pressure of $\mathrm{H}_{2} \mathrm{O}_{2}$ and to compare this with the theoretically expected relationship. Due to technical constraints, the exhaled air could only be measured via EBC and not by the Aero Laser monitor.

The Aero Laser device detects $\mathrm{H}_{2} \mathrm{O}_{2}$ online in the gas phase (ppb; detection limit $<50$ ppt in the gas phase). Using two enzymatic reactions it separately assesses the contributions from $\mathrm{H}_{2} \mathrm{O}_{2}$ and from other peroxides that may have similar fluorescence properties as $\mathrm{H}_{2} \mathrm{O}_{2}$ [20-22]. As atmospheric $\mathrm{H}_{2} \mathrm{O}_{2}$ rarely reaches very high concentrations, different levels of $\mathrm{H}_{2} \mathrm{O}_{2}$ were generated in a work bench (LaminAir $\mathrm{HB}$ 2448; Heraeus Instruments, Hanau, Germany) of about $0.5 \mathrm{~m}^{3}$ using whirled solutions of $\mathrm{H}_{2} \mathrm{O}_{2}$ concentrations at room temperature. The large volume ensured that the concentrations did not markedly change over the sampling time.

The efficiency of the inhalation filter (filter respirator type: A2B2E2K1HgNOP3 NR D CO; Sperian, Villers-Cotterêts, France) used for the measurements in subjects was assessed by determinations of $\mathrm{H}_{2} \mathrm{O}_{2}$ levels of air drawn either through or without the filter. The efficiency turned out to be 0.81 , i.e. at maximum $19 \%$ of peroxides passed the filter without a reduction of efficiency in the course of our study. Specific measurements for $\mathrm{H}_{2} \mathrm{O}_{2}$ indicated an efficiency near $100 \%$.

The second part of the study aimed at assessing the $\mathrm{H}_{2} \mathrm{O}_{2}$ contribution from inhaled to exhaled air of human subjects. This was achieved by performing EBC sampling with and without inhalation filter, as well as by using a mathematical model to compute the relationship between inhaled and exhaled $\mathrm{H}_{2} \mathrm{O}_{2}$ levels and to estimate a potential endogenous production of $\mathrm{H}_{2} \mathrm{O}_{2}$ from these data. For this purpose, we studied 12 patients with stable COPD of stages Global Initiative for Chronic Obstructive Lung Disease (GOLD) I-III ( $\mathrm{n}=2,5,5$, respectively) aged 60-80 years, and nine healthy nonsmokers aged 25-58 years. Two patients with COPD additionally suffered from asthma according to their medical history. We did not aim at revealing differences between these groups but at testing the applicability of our methods and therefore considered these group sizes as sufficient. Measurements were part of a local extension of a multi-centre COPD study and both had been approved by the local ethics committee.

\section{Measurements}

2-4 h prior to the collection of EBC from a subject, condensate sampling from ambient laboratory air was started (ambient air condensate (AAC)). This was achieved via an electric pump $\left(\sim 4 \mathrm{~L} \cdot \mathrm{min}^{-1}\right)$ continuously 
sucking air through the mouthpiece of the EcoScreen device for 90-240 min resulting in a sample volume of 1.5-6.5 mL. The continuous Aero Laser recordings indicated that ambient air concentrations were fairly stable over this period of time, although $\mathrm{H}_{2} \mathrm{O}_{2}$ levels in ambient air are generally known to depend on the time of the day. They also depend on meteorological conditions, e.g., correlate with ozone levels which also could be observed in our study.

After the collection of ambient air the measurements of subjects were started. EBC was collected for $15 \mathrm{~min}$ from subjects breathing at rest through a mouthpiece without inhalation filter while wearing a nose clip. After a short pause, a second EBC sample was collected for $15 \mathrm{~min}$ but, in this case, subjects inhaled through the filter which was placed at the inlet of a two-way valve. The subjects were allowed to briefly withdraw from the mouthpiece in case of coughing or accumulation of saliva. The mouthpiece of the EcoScreen device was positioned in a way as to avoid contamination of samples with saliva. Custom-made collection tubes were assembled from polypropylene components. All samples, either from ambient air or subjects, were stored immediately after collection in sealed collection tubes at $4^{\circ} \mathrm{C}$. The maximum time period until analysis was $3 \mathrm{~h}$ for ambient air samples and $1 \mathrm{~h}$ for breath samples. By repeated measurements of aliquots of samples we had ensured that $\mathrm{H}_{2} \mathrm{O}_{2}$ concentrations were stable. In parallel to condensate sample collection humidity and temperature of room air were recorded (Testo 445; Testo AG, Lenzkirch, Germany), air pressure values were taken from official records.

Analysis of $\mathrm{H}_{2} \mathrm{O}_{2}$ in condensate

$\mathrm{H}_{2} \mathrm{O}_{2}$ in the condensate was quantified by an optimised method based on that given by HysLop et al. [23]. The optimisation involved the comparison of consumables from different sources and the identification of those yielding the most reliable and reproducible data. For analysis, the non-fluorescent 4-hydroxyphenylacetic acid (H50004; Sigma Aldrich, St. Louis, MI, USA) was converted by the enzymatic reduction of $\mathrm{H}_{2} \mathrm{O}_{2}$ via horseradish peroxidase (p8375; Sigma Aldrich) into the stable, fluorescent product 2,2'-dihydroxybiphenyl-5,5'-diacetate. 96-well plates (237105, Nunc, Roskilde, Denmark) and water of p.a. quality (1.16754.9010, Merck KgaA, Darmstadt, Germany) were used. The fluorescence measurements were done in a plate reader (Varioskan Flash Multimode Reader, Thermo Scientific, Dreieich, Germany). To achieve the required precision in the determination of $\mathrm{H}_{2} \mathrm{O}_{2}$ in various matrices, we used standard addition to samples. Specifically, each sample was measured in aliquots including a standard curve of four concentrations. Moreover, assessments were done in duplicate. For data analysis, mean values were taken. Standard additions of water samples were used for the calculation of the detection limit $(0.34 \mu \mathrm{M})$. Reproducibility was $15 \%$ in the lower range of measured values (variation coefficient) and $7 \%$ in the mid range.

The $\mathrm{H}_{2} \mathrm{O}_{2}$ measurement within the Aero Laser AL2021 is based on the enzymatic reaction described above, which is known to be sensitive to all peroxides in a solution. Moreover, $\mathrm{H}_{2} \mathrm{O}_{2}$ is selectively destroyed by catalase (C100; Sigma Aldrich) in a parallel channel. The difference between the two signals yields the $\mathrm{H}_{2} \mathrm{O}_{2}$ concentration. As the levels of peroxides other than $\mathrm{H}_{2} \mathrm{O}_{2}$ were low, we used the $\mathrm{H}_{2} \mathrm{O}_{2}$ signal for all analyses.

\section{Computational model}

The purpose of the model was to answer the question, whether there is endogenous production of $\mathrm{H}_{2} \mathrm{O}_{2}$ in the lung despite the fact that, empirically and theoretically, $\mathrm{H}_{2} \mathrm{O}_{2}$ concentrations in exhaled air are lower than in inhaled air. The dependence of exhaled $\mathrm{H}_{2} \mathrm{O}_{2}$ on expiratory flow rate suggests that the major fraction is gaseous and originates in the airways [15]: this can be described by simple physical principles, whereas it does not seem possible within a simple model to accommodate for compounds not in vapour form.

Inhaled air undergoes a change in temperature and humidification in the lung. To compare ambient air with exhaled air, ambient air values were converted to BTPS conditions (body temperature ambient barometric pressure and saturated with vapour), using the measured relative humidity $\varphi$ (\%) and temperature $\mathrm{T}(\mathrm{K})$. Due to the humidification of air, i.e. addition of water molecules, $\mathrm{H}_{2} \mathrm{O}_{2}$ should be diluted in exhaled relative to inhaled air even if there is no absorption or production in the lung. We assumed that $\mathrm{H}_{2} \mathrm{O}_{2}$ and water froze out with the same efficiency in the device used.

First, we calculated a temperature- and humidity-dependent conditioning factor $\Gamma$ for water vapour. Using relative humidity $\varphi$, vapour pressure $e$, saturation vapour pressure $E$, absolute humidity $\rho_{\mathrm{w}}$, maximum absolute humidity $\rho_{\mathrm{w}, \max }$, the gas constant $R_{\mathrm{w}}$, and temperature $T$, the basic formulae are:

$$
\begin{aligned}
\varphi=\frac{e}{E} \cdot 100 \% & \approx \frac{\rho_{w}}{\rho_{w, \max }} \cdot 100 \% \\
\rho_{w, \max } & =\frac{E}{R_{w} \cdot T}
\end{aligned}
$$




$$
R_{w}=461.52 \frac{\mathrm{J}}{\mathrm{kgK}}
$$

Using this and the Magnus formula for the calculation of saturation vapour pressure (a good approximation from -45 to $60^{\circ} \mathrm{C}$ ), one obtains for the density of water vapour

$$
\rho_{w}=\frac{\varphi \cdot \rho_{w, \max }}{100 \%}=\frac{\varphi \cdot E}{100 \% \cdot R_{w} \cdot T}=\frac{\varphi}{100 \% \cdot R_{w} \cdot T} \cdot 4.59 \mathrm{Torr} \cdot \exp \left(\frac{17.62 \cdot(T-273 \mathrm{~K})}{243.12 \mathrm{~K}+(T-273 \mathrm{~K})}\right)
$$

This formula is valid for both inhaled (in) and exhaled (ex) air if the appropriate values for temperature and humidity are put in. The ratio of expiration to inspiration provides a factor for the change in water content due to reconditioning within the lung. The total reconditioning factor $\Gamma$ has to contain a further factor $f$ representing the change in the total volume of inhaled air resulting from the temperature change and from the change in the relative numbers of molecules at fixed ambient air pressure:

$$
\Gamma=\frac{\rho_{w, e x}}{\rho_{w, i n}} \cdot f=\frac{\varphi_{e x} \cdot T_{i n} \cdot E_{e x}}{\varphi_{\text {in }} \cdot T_{e x} \cdot E_{i n}} \cdot f
$$

With $P$ amb the ambient air pressure, the factor $f$ is:

$$
\begin{gathered}
f=\frac{P_{e x}}{P_{\text {in }}} \\
P_{\text {in }}=P_{a m b} \\
P_{e x}=\left(P_{a m b}-P_{w, i n}\right) \cdot \frac{T_{e x}}{T_{i n}}+P_{w, e x}
\end{gathered}
$$

Where upon

$$
P_{w}=\frac{\varphi}{100 \%} \cdot E
$$

This formula is based on the general gas equation. The change in volume of the real, isobaric change of state is equal to the pressure change at a theoretical, isochoric change of state. For the pressure $e$ from formula (1) we take the water vapour pressure $P_{\mathrm{w}}$. Thus the final result for the conditioning factor $\Gamma$ is:

$$
\Gamma=\frac{\rho_{w, e x}}{\rho_{w, i n}} \cdot f=\frac{\varphi_{e x} \cdot T_{i n} \cdot E_{e x}}{\varphi_{i n} \cdot T_{e x} \cdot E_{i n}} \cdot f=\frac{\varphi_{e x} \cdot T_{i n} \cdot E_{e x}}{\varphi_{i n} \cdot T_{e x} \cdot E_{i n}} \cdot \frac{\left(\left(P_{a m b}-\frac{\varphi_{i n}}{100 \%} \cdot E_{i n}\right) \cdot \frac{T_{e x}}{T_{i n}}+\frac{\varphi_{e x}}{100 \%} \cdot E_{e x}\right)}{P_{a m b}}
$$

Since the amount of $\mathrm{H}_{2} \mathrm{O}_{2}$ can be neglected in comparison to water, the ambient air vapour concentrations divided by the factor $\Gamma$ provide the expected vapour concentrations of $\mathrm{H}_{2} \mathrm{O}_{2}$ in exhaled air under the assumption that $\mathrm{H}_{2} \mathrm{O}_{2}$ is passed from inhaled to exhaled air without absorption or production. Any deviation from this prediction would point to either net production and/or absorption in the lung, except for the improbable case that absorption exactly balances production.

\section{Data analysis}

Mean values and interquartile ranges were used for the description of the data, Mann-Whitney U-tests for the comparisons of groups, and Wilcoxon matched-pairs signed-ranks tests for the comparison of conditions within groups. For the comparison of AAC and Aero Laser measurements, linear regression analysis was employed. The level of statistical significance was assumed at $\mathrm{p}=0.05$, without corrections for the multiplicity of tests. For analysis, the statistical software sigma plot 13.0 (Systat Software Inc., Erkrath, Germany) was used. The model computations were done in Excel (Excel 2010, Microsoft, Redmond, WA, USA).

\section{Results}

The comparison of $\mathrm{H}_{2} \mathrm{O}_{2}$ levels of artificially enriched ambient air measured by the two methods showed a linear relationship $(\mathrm{AAC}=2.02 \times$ AeroLaser +2.23 ; figure 1$)$. This directly allowed expressing $\mathrm{H}_{2} \mathrm{O}_{2}$ levels 
FIGURE 1 Relationship between values of $\mathrm{H}_{2} \mathrm{O}_{2}$ assessed in ambient air condensate (AAC) and by the Aero Laser atmospheric measuring device.

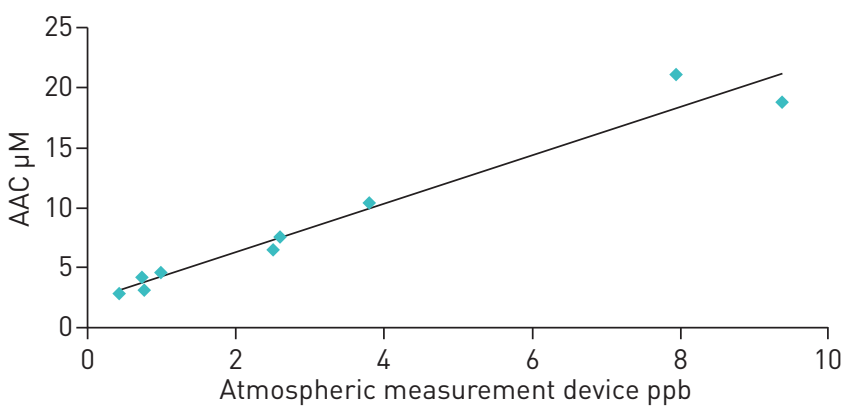

in condensate as equivalent partial pressures or volume fractions of $\mathrm{H}_{2} \mathrm{O}_{2}$. The fact that the intercept was greater than zero (95\% CI: $0.55-3.91$ ) and the slope greater than one (95\% confidence interval: $1.65-2.40$ ) indicated a systematic difference between the two readings, possibly due to the fact that the condensate method is sensitive to all peroxides, not only $\mathrm{H}_{2} \mathrm{O}_{2}$. The total peroxide readings from the Aero Laser device were difficult to calibrate in absolute terms and therefore not used.

The findings indicated that the major proportion of peroxides measured by the condensate method consisted of $\mathrm{H}_{2} \mathrm{O}_{2}$ suggesting that the computations based on vapour properties of inhaled and exhaled $\mathrm{H}_{2} \mathrm{O}_{2}$ were justified. The fact that during the measurements in patients ambient air levels of $\mathrm{H}_{2} \mathrm{O}_{2}$ correlated with those of ozone (figure 2) was expected from meteorological findings and supported the validity of measurements also in the range of lower $\mathrm{H}_{2} \mathrm{O}_{2}$ levels. Ozone data were taken from the records of the nearest measuring station of Munich Ambient Air Monitoring Programme (LfU Bavaria).

\section{Results in human subjects}

All subjects tolerated the measurements well, including the elevated resistance during inhalation through the filter. None of the subjects interrupted the sampling periods by withdrawing from the mouthpiece. The ambient air levels of $\mathrm{H}_{2} \mathrm{O}_{2}$ were not significantly different between the measurements of COPD patients and those of control subjects (figure 3; table 1). The same was true for ambient air pressure and temperature. In addition, neither the values assessed without inhalation filter nor those assessed with inhalation filter were significantly different between the two groups.

The analysis of values within the two groups showed much higher values of ambient $\mathrm{H}_{2} \mathrm{O}_{2}$ than exhaled $\mathrm{H}_{2} \mathrm{O}_{2}$ without inhalation filter (figure $3 \mathrm{a}$ versus $\mathrm{c} ; \mathrm{p}<0.001$ each). These differences disappeared when the room air values were multiplied with the reconditioning factor $\Gamma$ (figure 3 a versus b; pCOPD $=0.403$, pcontrol=0.480). In both groups, the levels of exhaled $\mathrm{H}_{2} \mathrm{O}_{2}$ with inhalation filter were lower than those without (figure 3 e versus $\mathrm{c}$; pCOPD $=0.010$, pcontrol $=0.003$ ). When comparing the values of exhaled $\mathrm{H}_{2} \mathrm{O}_{2}$ obtained with inhalation filter with the $\mathrm{H}_{2} \mathrm{O}_{2}$ values of room air that had been recalculated using the filtering as well as the reconditioning factor, there were still significant differences (figure $3 \mathrm{e}$ versus d; $\mathrm{p}<0.001$ each) suggesting an endogenous contribution to exhaled $\mathrm{H}_{2} \mathrm{O}_{2}$.

As there were no statistically significant differences, neither in absolute values nor in changes, between groups, data from both groups were pooled to illustrate the common finding (figure 4).

\section{Discussion}

Our findings indicate that the level of exhaled $\mathrm{H}_{2} \mathrm{O}_{2}$ in human subjects significantly depends on its level in inhaled ambient air. This was reflected by the observation that the use of an inhalation filter markedly reduced the levels of exhaled $\mathrm{H}_{2} \mathrm{O}_{2}$. At the same time, the difference against the levels to be expected from

FIGURE 2 Relationship between ambient air ozone concentrations loutdoor values taken from LfU Bavaria at the nearest measuring site) and ambient air condensate (AAC) concentrations of $\mathrm{H}_{2} \mathrm{O}_{2}$ (indoor).

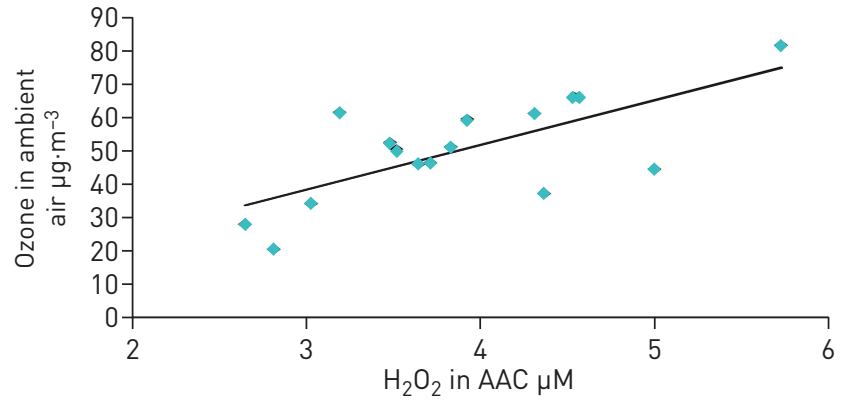




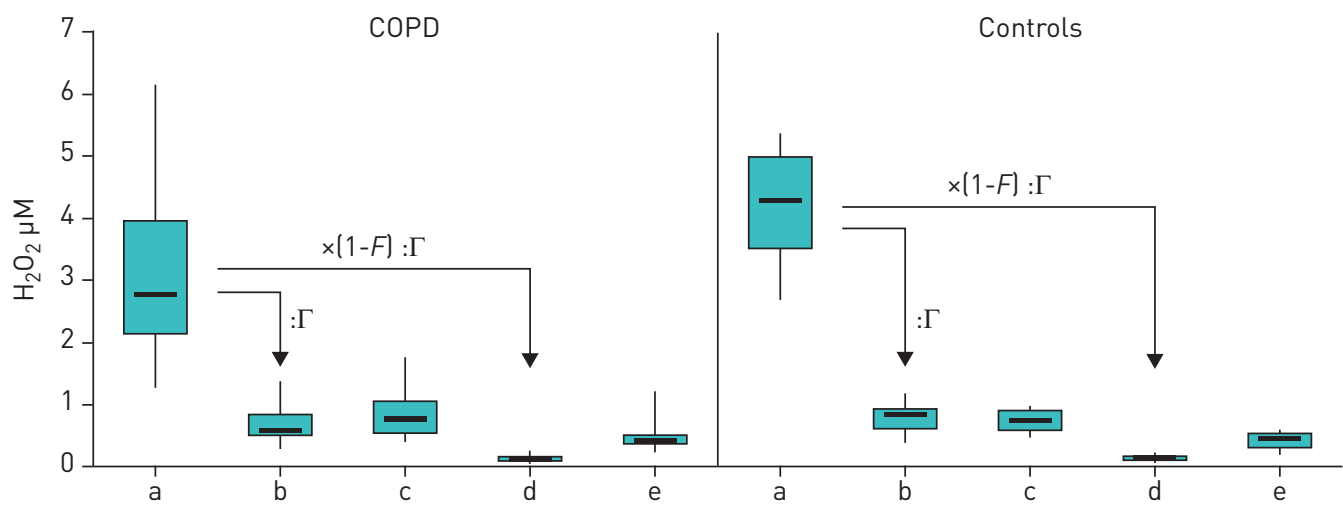

FIGURE 3 Comparison of exhaled $\mathrm{H}_{2} \mathrm{O}_{2}$ values in chronic obstructive pulmonary disease (COPD) patients (n=12) and control group (n=9). a) Raw ambient air concentrations. Calculated exhaled equivalents of ambient air concentration (b; taking account of the conditioning factor $\Gamma_{\text {; }}$ see Methods section) can be compared with the values measured in subjects without inhalation filter (c). Moreover, the calculated exhaled equivalents of ambient air concentration with inhalation filter (d; taking account of the conditioning factor $\Gamma$ and filter efficiency $F$; see Methods section) can be compared with the values measured in subjects using the inhalation filter (e). Data are presented as box plots, with boxes indicating quartile ranges $(25 \%, 75 \%)$, min and max as vertical lines, and median values as solid bars.

inhaled $\mathrm{H}_{2} \mathrm{O}_{2}$, if these were transformed into equivalent exhaled $\mathrm{H}_{2} \mathrm{O}_{2}$ levels, increased. The latter values were derived using a mathematical model that took into account the reconditioning of the inhaled air within the airways by humidification and warming. This reconditioning led to lower values of $\mathrm{EBC} \mathrm{H}_{2} \mathrm{O}_{2}$, i.e. relative to water vapour, in exhaled compared to ambient air. The measurements of ambient air via the condensate technique were validated by a commercial $\mathrm{H}_{2} \mathrm{O}_{2}$ analyser.

Exhaled $\mathrm{H}_{2} \mathrm{O}_{2}$ has been assessed in many studies on patients with airway diseases [24] but has been recognised to be difficult to measure [1], and it is not unreasonable to assume a publication bias towards positive associations. Part of the variability could be due to ambient air $\mathrm{H}_{2} \mathrm{O}_{2}$ [18] which has rarely been realised by researchers [19]. This would not pose a major problem if the ambient air levels would be much lower than the levels generated via endogenous $\mathrm{H}_{2} \mathrm{O}_{2}$ production in the exhaled air. However, the opposite seems true. This becomes obvious if the levels in exhaled air, which are generally given as molar concentrations in a collected fluid, are expressed as partial pressure of gaseous $\mathrm{H}_{2} \mathrm{O}_{2}$. This involves the assumption that $\mathrm{H}_{2} \mathrm{O}_{2}$ predominantly occurs as vapour in the gas phase which is suggested by the observation that the levels of exhaled $\mathrm{H}_{2} \mathrm{O}_{2}$ are flow-dependent [15]. That would be difficult to explain in terms of exhaled aerosols but is quite natural for gaseous $\mathrm{H}_{2} \mathrm{O}_{2}$ arising from the airways, in analogy to exhaled nitric oxide (NO) [25].

If one assumes that in the absence of endogenous $\mathrm{H}_{2} \mathrm{O}_{2}$ production all of the inhaled $\mathrm{H}_{2} \mathrm{O}_{2}$ is exhaled, its concentration in EBC would be lower than in AAC, since water vapour is added within the airways, thereby diluting the $\mathrm{H}_{2} \mathrm{O}_{2}$ when measured in solution. This reasoning explains the prima facie surprising fact that in terms of EBC levels the airways appear to be a sink and not a source for $\mathrm{H}_{2} \mathrm{O}_{2}$. Moreover, the

TABLE 1 Measured $\mathrm{H}_{2} \mathrm{O}_{2}$ values in chronic obstructive pulmonary disease (COPD) patients $(\mathrm{n}=12)$ and healthy control subjects $(\mathrm{n}=9)$ under different conditions, as well as relevant ambient air data

COPD

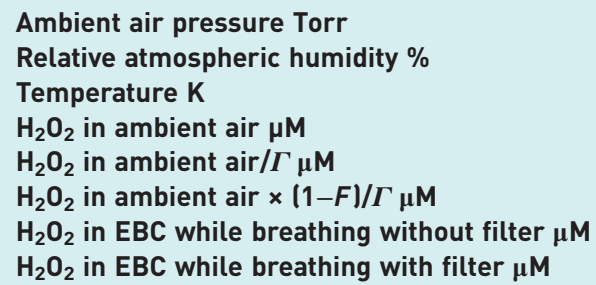

Data are presented as median (interquartile range). EBC: exhaled breath condensate.
$717.1(4.6)$

$45.1(4.4)$

$298.2(1.5)$

$2.774(1.815)$

$0.600(0.343)$

$0.780(0.510)$

$0.420(0.125)$
$0.114(0.065)$
Controls

716.8 (3.1)

$36.2(4.0)$

$299.2(1.3)$

$4.282(1.473)$

$0.864(0.335)$

$0.164(0.064)$

$0.748(0.317)$

$0.454(0.222)$ 


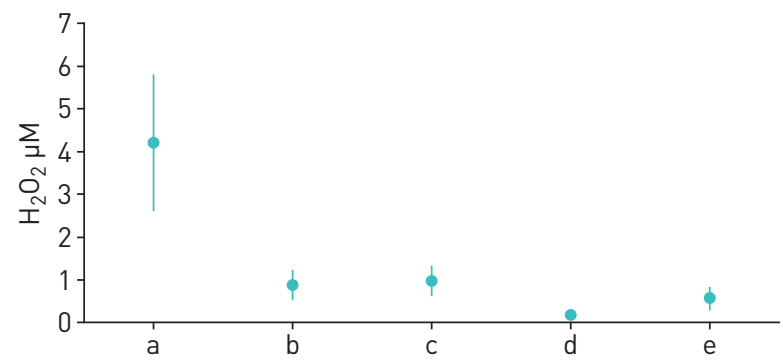

FIGURE 4 Comparison of exhaled $\mathrm{H}_{2} \mathrm{O}_{2}$ values pooled over all study subjects ( $n=21$ ). a) Raw ambient air concentrations. Calculated exhaled equivalents of ambient air concentration ( $b$; taking account of the conditioning factor $\Gamma$; see Methods section) can be compared with the values measured in subjects without inhalation filter (c). Moreover, the calculated exhaled equivalents of ambient air concentration with inhalation filter ( $d$; taking account of the conditioning factor $\Gamma$; see Methods section) can be compared with the values measured in subjects using the inhalation filter (e). Data are presented as mean \pm sD.

values of exhaled $\mathrm{H}_{2} \mathrm{O}_{2}$ measured in our study were similar to those expected solely from the inhaled ambient air. This would not seem to indicate a measurable endogenous $\mathrm{H}_{2} \mathrm{O}_{2}$ production. Assuming that $\mathrm{H}_{2} \mathrm{O}_{2}$ is transferred from the mucosa into the lumen by a diffusion process following the concentration gradient, this observation suggests that the mucosal concentration of $\mathrm{H}_{2} \mathrm{O}_{2}$ is not much larger than the equivalent arising from ambient air. Indeed, when measured at a very low expiratory flow rate, that was markedly below those achieved in tidal breathing for most of the breathing cycle, $\mathrm{H}_{2} \mathrm{O}_{2}$ levels were in the range found in the present study [15]. Under these conditions equilibrium between mucosa and lumen should be approached.

If the fraction of $\mathrm{H}_{2} \mathrm{O}_{2}$ in the airway lumen that is due to inhaled $\mathrm{H}_{2} \mathrm{O}_{2}$ is reduced by an inhalation filter, the gradient between mucosa and lumen is expected to increase. Accordingly, in our measurements there was a significant difference between the values computed from inhaled $\mathrm{H}_{2} \mathrm{O}_{2}$ and the values actually measured. This pointed towards endogenous $\mathrm{H}_{2} \mathrm{O}_{2}$ production masked by inhaled $\mathrm{H}_{2} \mathrm{O}_{2}$. At the same time, the between-subject variation of the measured values in exhaled air was reduced, again supporting the assumption that part of the well-known variability of $\mathrm{H}_{2} \mathrm{O}_{2}$ levels in $\mathrm{EBC}$ is due to the variation in inhaled $\mathrm{H}_{2} \mathrm{O}_{2}$. When analysing $\mathrm{H}_{2} \mathrm{O}_{2}$ values obtained with the inhalation filter, we did not observe a systematic difference between the control group and COPD patients, most of them with mild to moderate disease. This, however, was also true for the values obtained in the conventional manner without filter.

Our findings indicate that exhaled $\mathrm{H}_{2} \mathrm{O}_{2}$ levels should not be determined without an inhalation filter removing most of the ambient air $\mathrm{H}_{2} \mathrm{O}_{2}$. This suggests a critical re-examination of the bulk of literature on exhaled $\mathrm{H}_{2} \mathrm{O}_{2}$ that has been accumulated over the years. Ambient air $\mathrm{H}_{2} \mathrm{O}_{2}$ levels are unlikely to be available in the retrospective, but it might be possible to re-analyze data by taking into account ambient air ozone levels which are correlated with $\mathrm{H}_{2} \mathrm{O}_{2}$ and much more likely to be available for the site and the time of the measurements.

\section{REFERENCES}

1 van Beurden WJC, Dekhuijzen PNR, Harff GA, et al. Variability of exhaled hydrogen peroxide in stable COPD patients and matched healthy controls. Respiration 2002; 69: 211-216.

2 Horvath I, Donnelly LE, Kiss A, et al. Combined use of exhaled hydrogen peroxide and nitric oxide in monitoring asthma. Am J Respir Crit Care Med 1998; 158: 1042-1046.

3 Emelyanov A, Fedoseev G, Abulimity A, et al. Elevated concentrations of exhaled hydrogen peroxide in asthmatic patients. Chest 2001; 120: 1136-1139.

4 Teng Y, Sun P, Zhang J, et al. Hydrogen peroxide in exhaled breath condensate in patients with asthma: a promising biomarker? Chest 2011; 140: 108-116.

5 Jobsis Q, Raatgeep HC, Hermans PWM, et al. Hydrogen peroxide in exhaled air is increased in stable asthmatic children. Eur Respir J 1997; 10: 519-521.

6 Effros RM, Su J, Casaburi R, et al. Utility of exhaled breath condensates in chronic obstructive pulmonary disease: a critical review. Curr Opin Pulm Med 2005; 11: 135-139.

7 Dekhuijzen PN, Aben KK, Dekker I, et al. Increased exhalation of hydrogen peroxide in patients with stable and unstable chronic obstructive pulmonary disease. Am J Respir Crit Care Med 1996; 154: 813-816.

8 Lee W, Thomas PS. Oxidative stress in COPD and its measurement through exhaled breath condensate. Clin Transl Sci 2009; 2: 150-155.

9 Nowak D, Kasielski M, Antczak A, et al. Increased content of thiobarbituric acid-reactive substances and hydrogen peroxide in the expired breath condensate of patients with stable chronic obstructive pulmonary disease: no significant effect of cigarette smoking. Respir Med 1999; 93: 389-396.

10 Montuschi P. Exhaled breath condensate analysis in patients with COPD. Clin Chim Acta 2005; 356: 22-34.

11 Wewel AR, Crusius JA, Gatzemeier U, et al. Time course of exhaled hydrogen peroxide and nitric oxide during chemotherapy. Eur Respir J 2006; 27: 1033-1039. 
12 Stolarek RA, Potargowicz E, Seklewska E, et al. Increased $\mathrm{H}_{2} \mathrm{O}_{2}$ level in exhaled breath condensate in primary breast cancer patients. J Cancer Res Clin Oncol 2010; 136: 923-930.

13 Jobsis RQ, Schellekens SL, Fakkel-Kroesbergen A, et al. Hydrogen peroxide in breath condensate during a common cold. Mediators Inflamm 2001; 10: 351-354.

14 Rahman I, Biswas SK. Non-invasive biomarkers of oxidative stress: reproducibility and methodological issues. Redox Rep 2004; 9: 125-143.

15 Schleiss MB, Holz O, Behnke M, et al. The concentration of hydrogen peroxide in exhaled air depends on expiratory flow rate. Eur Respir J 2000; 16: 1115-1118.

16 Rosias PPR, Dompeling E, Hendriks HJE, et al. Exhaled breath condensate in children: Pearls and pitfalls Pediatr Allergy Immunol 2004; 15: 4-19.

17 Harrison CM, Andersen CC. Exhaled breath measures of inflammation: are they useful in neonatal chronic lung disease? Arch Dis Child 2005; 90: F6-F10.

18 Schöne E. Ueber das atmosphärische Wasserstoffhyperoxyd. Berichte der deutschen chemischen Gesellschaft 1874; 7: 1693-1708.

19 Knobloch $\mathrm{H}$, Becher $\mathrm{G}$, Decker $\mathrm{M}$, et al. Evaluation of $\mathrm{H}_{2} \mathrm{O}_{2}$ and $\mathrm{pH}$ in exhaled breath condensate samples: methodical and physiological aspects. Biomarkers 2008; 13: 319-341.

20 Acker K, Kezele N, Klasinc L, et al. Atmospheric $\mathrm{H} 2 \mathrm{O} 2$ measurement and modeling campaign during summer 2004 in Zagreb, Croatia. Atmos Environ 2008; 42: 2530-2542.

21 Balasubramanian R, Husain L. Observations of gas-phase hydrogen peroxide at an elevated rural site in New York. J Geophys Res Atmos 1997; 102: 21209-21220.

22 Lazrus AL, Kok GL, Lind JA, et al. Automated fluorometric method for hydrogen-peroxide in air. Anal Chem 1986; 58: 594-597.

23 Hyslop PA, Sklar LA. A quantitative fluorimetric assay for the determination of oxidant production by polymorphonuclear leukocytes: its use in the simultaneous fluorimetric assay of cellular activation processes. Anal Biochem 1984; 141: 280-286.

24 Borrill ZL, Roy K, Singh D. Exhaled breath condensate biomarkers in COPD. Eur Respir J 2008; 32: 472-486.

25 Jorres RA. Modelling the production of nitric oxide within the human airways. Eur Respir J 2000; 16: 555-560. 